\title{
O processo de renovação do Serviço Social no Uruguai*
}

\section{Renewal of Social Work Process in Uruguay}

\section{Luis Acosta**}

Resumo- Este artigo analisa o processo de renovação do Serviço Social no Uruguai, ao longo de um ciclo histórico que compreende o período da ditadura (1973-1984). A renovação profissional começou com a aprovação do novo currículo da Escola Universitária de Serviço Social no ano de 1966, no mesmo ano em que se realiza o II Seminário Regional Latino-americano de Serviço Social na cidade de Montevidéu. Na ditadura a reflexão e prática profissional renovadora desloca-se fora do âmbito universitário, enquanto o movimento estudantil encabeça a resistência no interior da universidade. Finalizada a ditadura o debate profissional retorna ao espaço universitário na experiência das "Oficinas de Teoria e Prática Profissional". Este processo deu lugar ao surgimento de tendências ou perspectivas profissionais que são brevemente apresentadas. O encerramento da Escola Universitária de Serviço Social e a criação do Departamento de Trabalho Social, no quadro do processo de redemocratização, finalizam um ciclo do processo de renovação do Serviço Social no Uruguai. Palavras-chave: história do Serviço Social; reconceituação; teoria e prática do Serviço Social, Serviço Social Crítico.

\begin{abstract}
This article examines the process of renewing Social Service in Uruguay over an historical cycle which covers the period of the dictatorship (1973-1984). A professional renewal began with the adoption of the University School of Social Work new curriculum in 1966, the same year in which takes place the II Latin American Regional Seminar of Social Service in Montevideo. In the dictatorship regime the reflection and renewal professional practice moves outside the university circle, while the student movement heads the resistance within the university. Ended the dictatorship professional debate returns to the university space with the experience of "Workshops of Professional Theory and Practice". This process gave birth to trends or professional perspectives briefly presented. The closing of the University School of Social Service and the creation of Social Work Department, as part of the re-democratization process, finalize a cycle of renewal of Social Service process in Uruguay.
\end{abstract}

Keywords: history of Social Work; reconceptualization; theory and practice of Social Work; Critical Social Work.

\footnotetext{
* Artigo construído com base no terceiro capítulo da tese de doutorado intitulada "O Processo de Renovação do Serviço Social no Uruguai", orientada pelo Professor J. P. Netto, defendida no ano 2004, no Programa de Pós-graduação em Serviço Social da ESS/UFRJ.

** Assistente social e doutor em Serviço Social (UFRJ). Professor Adjunto do Departamento de Fundamentos TeóricoMetodológicos do Serviço Social da Escola de Serviço Social da Universidade Federal do Rio de Janeiro. Correspondência: ESS/UFRJ. Campus Praia Vermelha. Av. Pasteur, 250 - Praia Vermelha - Rio de Janeiro. RJ. CEP: $22290-240$. E-mail:<luis@ess.ufrj.br>.
} 


\section{Introdução}

No Uruguai, assim como nos países da América Latina, no final dos anos cinquenta, começava uma crise provocada pelo esgotamento do processo de industrialização por substituição de importações, logo depois de finalizada a II Segunda Guerra Mundial (1939-1945) e a Guerra da Coreia (1950-1953). Esta crise agudizava os problemas do particular desenvolvimento do capitalismo no nosso continente. Tratava-se dos problemas criados pelo caminho oligárquico-dependente, na expressão do Cueva (1987), que caracteriza o predomínio dos processos "pelo alto", no quadro da inserção internacional subalterna na época do capitalismo dos monopólios.

Esta situação latino-americana, com evidentes particularidades nacionais, teve uma inflexão fundamental com o triunfo da revolução cubana em 1959 e seu posterior curso socialista. Cuba levantava a possibilidade de um caminho democrático-popular, "jacobino", pode-se dizer, em contraposição ao caminho reacionário, oligárquico-dependente da tradição latinoamericana. A revolução cubana, num cenário internacional pautado pela Guerra Fria (1947-1989), teve um impacto fundamental nos processos sociopolíticos dos anos sessenta.

No caso dos assistentes sociais enquanto trabalhadores, e do Serviço Social como instituição, esta situação latino-americana deu lugar a um processo de renovação e de reconceituação, através de um complexo de mediações institucionais, políticas, culturais, que têm sido objeto de múltiplas análises.

O movimento de renovação do Serviço Social teve início por volta de 1965, com a realização do I Seminário Regional Latino-Americano de Serviço Social, em Porto Alegre. No ano de 1965 foi criada também a Associação Latino-Americana de Escolas de Serviço Social (ALAESS'1), que depois (a partir de 1974), através do Centro Latino-Americano de Trabalho Social (CELATS), realizou uma significativa contribuição ao desenvolvimento do Serviço Social, especialmente durante o período ditatorial nos países do Cone Sul. No ano de 1970, uma fratura entre o grupo ECRO (editora argentina dirigida por Juan Barreix) e o grupo de assistentes sociais, que logo depois se reuniriam no CELATS, constituiu-se num divisor de águas entre o momento da renovação profissional e a reconceituação. (FALEIROS, 1987).

Entendemos que o processo de reconceituação do Serviço Social, nas suas formas mais radicalizadas, caracterizou-se pela pretensão de refundar a profissão. Isto é, na categoria profissional colocava-se a proposta de mudar as bases de sustentação sócio-ocupacional (ou seja, o lugar na divisão sociotécnica do trabalho), assim como também os supostos teóricos

\footnotetext{
${ }^{1}$ No ano de 1977 esta organização mudará de nome trocando "Serviço Social" por "Trabalho Social" passando a ser então : Associação Latino-americana de Escolas de Trabalho Social (ALAETS).
} 


\section{AeVistg all paUtg}

\} O PROCESSO DE RENOVAÇÃO DO SERVIÇO SOCIAL NO URUGUAI - ACOSTA, L. \}

e meta-teóricos nos quais se fundamentava o Serviço Social até esse momento (que então passava a ser chamado de "tradicional"). Esta pretensão de refundar, sobre novas bases, o Serviço Social, expressou-se até na mudança do nome do Serviço Social, que passou a ser chamado de "Trabalho Social".

O movimento da reconceituação não finalizou por esgotamento da sua capacidade crítica. Sua crise foi uma expressão da "crise do projeto revolucionário latino-americano" (NETTO, 1975, p. 73). Ele foi interrompido violentamente pela emergência das ditaduras militares dos anos setenta nos países onde o processo de mobilização político-social estava mais avançado (Chile, Argentina, Uruguai), fazendo parte de uma estratégia contrarrevolucionária mais ampla promovida pelos EUA. O caso do Brasil é muito diferenciado, em razão de a ditadura ter começado precocemente (em meados dos anos sessenta), tendo se constituído em um ensaio da solução "contrarrevolucionária preventiva", por parte do imperialismo dos EUA, para enfrentar o processo de crescente mobilização social. (NETTO, 2001).

O Serviço Social no Uruguai, diferentemente do caso do Brasil, iniciou seu desenvolvimento vinculado de forma subordinada à instituição médica (ao movimento higienista) e, em menor medida, ao movimento católico (ACOSTA, 1998). Isto significou que seu desenvolvimento foi marcado fundamentalmente pelo reformismo social de origem burguês positivista antes que pelo conservadorismo restaurador do movimento católico.

Com efeito, a primeira experiência de formação de profissionais aconteceu no interior da Faculdade de Medicina, no ano de 1927. Em 1936, a formação de assistentes sociais (que naquela época eram denominadas "visitadoras sociais") passou para a Escola de Sanidade Pública e Serviço Social, que funcionava como uma repartição do recentemente criado Ministério da Saúde Pública².

No ano seguinte foi criada a Escola de Serviço Social do Uruguai, de origem católica, que teve uma participação bastante marginal no processo de formação de profissionais do Serviço Social. No seu primeiro currículo esta Escola trabalhava com uma concepção do Serviço Social como "forma moderna de apostolado". Assim: "El Servicio Social es, en suma, una forma moderna de apostolado. Y yo diría más: es una forma moderna, actual, de cumplir el mandamiento supremo de la caridad". (CHIARINO apud GERPE DE BELLINI et al., 1980, p. 48).

Com este currículo, formaram-se 87 profissionais do Serviço Social entre os anos de 1937 e 1952, sendo que é necessário lembrar que no curso de visitadoras sociais da Faculdade de Medicina tinham-se formado, entre os anos de 1927 e 1934, 161 visitadoras sociais. Este currículo foi modificado de forma parcial no ano de 1953, mudando basicamente a denominação de Visitadora Social para Assistente Social.

\footnotetext{
${ }^{2}$ Segundo Dupont (1983) a Lei Orgânica da Saúde Pública do 16/XI/1933 estabeleceu no seu artigo 41 a criação dessa escola que continuará com a formação iniciada no Instituto de Higiene da Faculdade de Medicina.
} 
O currículo voltou a ser modificado em 1966, contando para isto com a assessoria da Escola de Serviço Social de São Paulo, procurando uma maior sintonia com o processo de renovação profissional que se desenvolvia na América Latina. Voltou, ainda, a ser modificado no ano de 1970, já na ditadura, impulsionando um perfil profissional "educativo", "conscientizador" e "assistencial", que privilegia a intervenção em nível de caso e de grupo, com uma ênfase importante na "vivência" do profissional.

Nos anos cinquenta do século passado, o campo de intervenção profissional tinha se ampliado como resultado das transformações do Estado, que assumiu novas funções como promotor do desenvolvimento. Ampliouse também como resultado da nova inserção nas relações internacionais de pós-guerra, que levou a reforçar a hegemonia dos EUA no continente sul-americano.

Estas mudanças colocavam a necessidade da modernização técnica no interior do horizonte do reformismo social (ou do progressismo). Surge assim, nessa década, como resultado da cooperação com a ONU (em que tiveram um papel destacado as assistentes sociais chilenas Valentina Maidagan de Ugarte e Rebeca Bustos Julien), outra escola de Serviço Social em 1954, de orientação desenvolvimentista, que primeiro esteve alocada no Ministério da Saúde Pública e logo, em 1960, passou para o Ministério de Instrução Pública e da Previdência Social.

No mesmo ano de 1954, tiveram início na Universidade de República os estudos para a criação de uma escola que se concretizou três anos mais tarde. As duas escolas públicas coexistiram durante uma década, até que a escola do "Ministério", como ficou conhecida, passou a depender do Ministério de Trabalho e Seguridade Social, na forma de Instituto de Serviço Social, perdendo suas funções docentes (os professores e alunos passam para a escola universitária e os diplomas expedidos por essa escola são reconhecidos pela Universidade). (ORTEGA, 2003).

\section{O II Seminário Regional Latino-americano de Serviço Social: Serviço Social, evolução e revolução}

No ano de 1966 foi realizado, em Montevidéu, o II Seminário Regional Latino Americano de Serviço Social ${ }^{3}$, cujo o tema principal era "Serviço Social: evolução e revolução".

O Seminário foi organizado em torno de três eixos: a) Problemas metodológicos do Serviço Social, b) Serviço Social: evolução e revolução, e c) Política do Serviço Social no desenvolvimento. (DUPONT, 1983). Em relação ao segundo ponto (Serviço social: evolução e revolução), apre-

\footnotetext{
${ }^{3}$ O primeiro seminário aconteceu em Porto Alegre no ano de 1965, e é considerado como o início do processo de reconceitualização.
} 


\section{AeVistg all paUtg}

\} O PROCESSO DE RENOVAÇÃO DO SERVIÇO SOCIAL NO URUGUAI - ACOSTA, L. \}

sentaram-se três conferências principais, uma delas a cargo de Herman Kruse sobre O Serviço Social nos países capitalistas; outra, a cargo de Raquel Cortinas, sobre O Serviço Social nos países socialistas, e a terceira ficou a cargo de Enrique Iglesias sobre O Serviço Social nos países subdesenvolvidos.

Interessa-nos particularmente a contribuição de Enrique Iglesias, porque ele foi uma figura muito relevante no processo de renovação profissional. Foi o diretor da escola universitária, a partir do ano de 1972, até ser demitido com o Golpe de Estado de 1973. Retornou a esse cargo no ano de 1985 com a redemocratização da universidade, permanecendo até o ano de 1989. Foi uma figura que, infelizmente, publicou muito pouco; no entanto, desenvolveu um importante trabalho docente e um trabalho de organização, planejamento e gestão de recursos no âmbito da universidade. Teve um importante papel no processo de constituição da Faculdade de Ciências Sociais e na criação do Departamento de Trabalho Social dentro dela. Sua atuação esteve bastante ligada com aqueles assistentes sociais que gravitavam em torno da organização Equipos Consultores Asociados (que nós identificamos como "modernizadores") sem que, no entanto, se confunda inteiramente com esses assistentes sociais.

Enrique Iglesias centrou sua conferência na relação entre Serviço Social e subdesenvolvimento. Iglesias (1966) questiona nesta conferência os princípios éticos do serviço social tradicional por causa do seu caráter abstrato, chamando a atenção para a necessidade de definir os valores, os métodos e as técnicas para uma situação concreta: aqui e agora. Esta necessidade de levar em consideração as circunstâncias concretas leva a perceber a "presença de estruturas socioeconômicas que aparecem como causa geral, fator desencadeante do acúmulo de misérias e penúrias que limitam, freiam e travam o desenvolvimento do indivíduo e da comunidade nacional". (IGLESIAS, 1966, p. 73).

Por esta razão, quer dizer, por causa da natureza estrutural dos problemas sociais, é que o Serviço Social deve desenvolver sua atividade profissional em dois planos coordenados: a) na participação do planejamento que assegure o pleno desenvolvimento nacional, contribuindo na tomada de consciência pública sobre as falhas da organização social presente, e b) na tarefa direta de superação de carências impulsionando modificações parciais a nível individual ou grupal, com uma perspectiva da projeção social das mesmas. Aqui, Iglesias (1966) está retomando as definições do currículo de 1966, às quais seguramente contribuiu pessoal e diretamente na sua formulação.

Em relação às causas determinantes do subdesenvolvimento, Iglesias (1966, p. 73) observa que são:

essencialmente históricas, producto del desenvolvimiento desigual del capitalismo, de la penetración colonial e imperialista y del mantenimiento de relaciones de producción precapitalistas subsistiendo 
con sectores de explotación capitalista imprecisa, limitada y orientada en beneficio del país imperial.

Em relação a esta situação, Iglesias (1966, p. 75) questiona os princípios que devem presidir o Desenvolvimento Econômico e Social (DES): solidariedade, autenticidade, harmonia, e democracia, sustentando que "em uma sociedade classista o DES não poderá ter lugar sem luta de classes como o marcam todos os exemplos históricos".

Segundo este autor, para alcançar o desenvolvimento econômico planejado são necessárias algumas condições:

- Superar a crise socioeconômica provocada pela penetração imperialista e seus efeitos;

- Um governo representativo dos interesses da maioria de população;

- Poupança e investimentos adaptados às possibilidades da população;

- Assumir um modelo determinado em função das condições locais.

O assistente social na sua prática deve investigar, diagnosticar e tratar os problemas sociais que, ainda que possam obedecer a causas de ordem individual, na maioria das ocasiões reconhecem uma origem estrutural.

Para orientar a formação profissional, Iglesias (1966) sustentava que primeiramente era necessário alcançar um grau de autonomia cultural, em relação aos valores que devem nortear o desenvolvimento nacional. No que diz respeito ao plano específico do Serviço Social, o profissional deve atuar como agente de mudança social, de tal forma que possa fazer parte de uma equipe técnica responsável pelo planejamento e execução do desenvolvimento social.

A seguir, Iglesias (1966) indaga se não existirá conflito entre o planejamento e o respeito pela individualidade de indivíduos, grupos e comunidades. Neste caso, trata-se de buscar um ponto de contato entre o planejamento e a população que torne possível a conciliação entre interesses antagônicos. Caso o conflito se prolongue no tempo, corresponde ao assistente social explicitar uma consciência social, que leve o indivíduo a admitir os interesses coletivos do grupo ou da nação.

Por último, Iglesias (1966) recorre a uma metáfora para explicar o lugar do assistente social como pesquisador. Para este autor, o assistente social enxerga a realidade social "de perto", aproximando-se cordialmente dos homens. Sem esta aproximação à realidade sócio-humana não é possível entender nada. Esta forma de aproximação à realidade social está relacionada ao que poderia ser denominado como um "sociólogo descalço" antes que um sociólogo prático. 


\section{A Escola Universitária de Serviço Social da Universidade da República}

Primeiramente temos que lembrar que, no Uruguai daqueles dias, a Universidade da República (UDELAR) era a única universidade no país ${ }^{4}$.

No ano de 1958 (ano eleitoral, que vai marcar a derrota eleitoral do governo do Partido "Colorado", que tinha governado durante quase um século), o Parlamento aprovou uma nova Lei Orgânica da Universidade (URUGUAI, 1958), que estabeleceu sua forma de funcionamento assim como sua organização. Esta Lei tinha sido elaborada pela própria Universidade, e nela se exprimiam os ideais progressistas dos universitários forjados desde a segunda década do século XX, inspirados no movimento reformista de Córdoba. No processo de discussão parlamentar desta Lei, desenvolveu-se uma grande mobilização estudantil junto com o movimento operário.

Foi no seio deste processo reformista com apoio popular que se criou a Escola Universitária de Serviço Social, no ano de 1957, no seio da Universidade da República (ou seja, um ano antes da aprovação da Lei Orgânica da Universidade) ${ }^{5}$.

A fundação da Escola Universitária de Serviço Social (EUSS) foi resultado dos trabalhos de uma comissão nomeada pelas autoridades universitárias no ano de 1954. Formavam parte desta comissão os professores Issac Ganon e Judith Dellepian de Roma, sendo que esta última exerceu o cargo de diretora da escola, designada pelo Conselho Diretivo Central, entre os anos de 1957 e 1960.

A fundamentação para a criação da Escola Universitária era de caráter para-jurídico. Sustentava-se que na sociedade uruguaia já existia uma proteção legal abrangente para todos os indivíduos; entretanto alguns indivíduos não conseguiam usufruir dos benefícios consagrados pela legislação social. Para a comissão esta seria a tarefa dos assistentes sociais, ou seja, fazer com que os indivíduos conseguissem usufruir dos direitos sociais consagrados pela legislação.

Na fundamentação, sustentava-se que os conceitos de caridade e de filantropia já têm sido substituídos pelo "princípio da obrigação social universal de garantir a todo ser humano a tutela contra as consequências

\footnotetext{
${ }^{4}$ Foi assim até o ano 1984, quando a ditadura, já moribunda, autoriza a criação da Universidade Católica do Uruguai "Dámaso Antonio Larrañaga" (UCUDAL). Esta nova universidade vai se incorporar à velha Escola de Serviço Social do Uruguai (criada no ano de 1937).

${ }^{5}$ Vale lembrar que naquele momento existiam duas escolas de formação profissional. A primeira, era a escola de origem católica fundada em 1937 (Escola de Serviço Social do Uruguai), associada à União Católica Internacional de Serviço Social e à Associação Internacional de Serviço Social e, a segunda era a escola, de caráter público, que atuava na órbita do Ministério de Instrução Pública e Previdência Social, fundada no ano de 1954 no âmbito do Ministério de Saúde Pública, e que no ano 1960 passou ao ministério citado primeiramente. Esta última escola deixou de funcionar como tal depois de um acordo com a Escola Universitária de Serviço Social, no ano de 1967, passando a serem reconhecidos pela Universidade da República todos os profissionais formados por ela. De fato a maioria dos docentes daquela escola também já trabalhavam na nova escola de caráter universitário.
} 
negativas que advém dos riscos da vida individual, familiar e coletiva" (DI CARLO, 1966, p. 141). Esta concepção estava fundamentada na Lei de Assistência Social de 1910:

El derecho a la asistencia es deber de la sociedad, es una obligación exigible [...] No hay que olvidar que no pueden presentarse las sociedades existentes como la encarnación del principio de que las recompensas deben ser proporcionais a los méritos de cada uno [...] Sólo por hipocresía o por timidez - agregabam - se puede negar que vivimos en una sociedad fundada sobre la injusticia. La asistencia pública es una reparación parcial de estas injusticias [...] El derecho a la asistencia es un compensación de las injusticias sociales, y es una consecuencia de la solidaridad que existe entre los hombres (Lei de Assistência So-cial apud DI CARLO, 1966, p. 14).

Entre os anos de 1960 e 1964, ocupou a direção da Escola, eleito pelo claustro da escola, o professor Dr. Dionísio J. Garmendia (advogado e sociólogo). Durante um período de aproximadamente 15 meses, este diretor foi substituído, por causa de um pedido de afastamento para férias, pelo Professor Spencer Díaz ${ }^{6}$. No entanto, a crise que a Escola atravessou no ano de 1969 não foi impedimento para o início da implementação do novo currículo a partir do ano de 1967, que tinha sido aprovado no ano de 1966 a partir de um documento preparado pelo Centro de Estudantes Universitários de Serviço Social (CEUSS).

Para o período de 1965 até 1969, foi eleito o Professor Enrique Di Carlo, que levou adiante uma gestão fortemente questionada, principalmente pelo segmento estudantil junto com alguns professores. Estes questionamentos tiveram como resultado a "intervenção" da Escola por parte das autoridades universitárias ao longo de dois anos, até a eleição do Professor Enrique Iglesias no ano de 1972.

Esta foi a primeira vez que a direção da Escola esteve nas mãos de um assistente social ${ }^{7}$. O mandato deste diretor foi interrompido pelo advento da ditadura em junho de 1973, que afastou todas as autoridades universitárias eleitas em processos democráticos realizados em conformidade com a Lei Orgânica da Universidade.

\section{A reforma curricular de 1966}

Quase desde o início das atividades da escola e, particularmente, a partir do movimento estudantil, surgiu a necessidade de uma revisão

6 Esta informação não foi possível de ser verificada em fontes documentais e foi obtida através de entrevista com o ex-secretário administrativo da escola: Roberto Etcheverry.

7 Em verdade, Enrique Iglesias, ainda não estava formado, o que só aconteceu em 1975, mas já era professor da disciplina "Introdução ao Serviço Social" desde o ano de 1968, quando ganhou por concurso o cargo de Encarregado dessa disciplina, que tinha ficado vago pelo falecimento da professora Danielle Duprey de Nitrosso. 


\section{AeVistg all paUtg}

\} O PROCESSO DE RENOVAÇÃO DO SERVIÇO SOCIAL NO URUGUAI - ACOSTA, L. \}

curricular que se materializou com o novo currículo de 1966, implantado a partir do ano seguinte. Em termos gerais este currículo pode ser identificado com as propostas desenvolvimentistas daquela época.

No novo currículo (CEUSS, 1966) afirma-se que a ação social do serviço social se desenvolve em dois planos. Em um primeiro plano, a ação profissional orienta-se explicitamente pela realização de modificações estruturais, colaborando no planejamento em nível nacional, sendo sua função particular tudo o que diz respeito ao "ajuste consciente entre estruturas e grupos humanos" (CEUSS, 1966). Neste plano, sustenta-se que quando não existem recursos suficientes para a realização de programas de transformação, o Serviço Social deverá promover a tomada de consciência pública das falhas na organização social vigente.

O outro plano de atuação profissional se constitui por tudo aquilo que é tarefa direta. Neste campo de atuação, o currículo exemplifica a atuação direta com a promoção de iniciativas de cooperativização e de autorregulação da vida social de localidades. É sintomática a referência ao cooperativismo e à autorregulação das localidades, porque o cooperativismo, tanto de consumo quanto de produção (especialmente este último), será um novo campo de intervenção profissional por parte dos assistentes sociais identificados com a perspectiva ${ }^{8}$ que denominamos como "sociológica" ou "modernizadora" nos anos setenta.

Esta referência ao cooperativismo nos leva a pensar que a alusão às "novas formas de organização social" (CEUSS, 1966) por parte dos trabaIhadores se identifica com esta forma de organização da produção. Tanto o cooperativismo de produção quanto o desenvolvimento local são alternativas de origem social-cristã, assim como o liberalismo econômico até o socialismo estatizante dos países do "socialismo real".

Observe-se que a influência do cooperativismo nos setores progressistas da sociedade daquela época foi tão marcante que até o movimento guerrilheiro "Tupamaros" exigiu, entre outras demandas como condição para sua rendição, a criação de uma cooperativa de pescadores.

O que queremos destacar é que o modelo que está na cabeça dos "modernizadores" uruguaios não é a organização técnico-burocrática da produção do capitalismo dos monopólios (como no Seminário de Araxá no Brasil), e sem a organização cooperativa de produção como uma "terceira via" entre o socialismo, por assim dizer, "estatizante", e o capitalismo liberal.

Uma última característica a ser sublinhada é a pretensão de criação da pós-graduação lato sensu (especializações), que infelizmente não chegou a ser implementada, tanto pela falta de recursos quanto pela duração tão curta deste novo currículo que, havendo começado sua implementação em 1967, em meados de 1973, com o advento da ditadura e a intervenção da universidade, deixou de vigorar.

${ }^{8}$ Ver mais a frente, no último item, a caraterização das perspectivas. 
Nesses sete anos e meio, formaram-se poucos profissionais, já que a própria dinâmica da vida universitária, com frequentes interrupções do calendário regular, dificultava a culminação dos estudos nos prazos previstos pelo novo currículo. A maior parte dos alunos finalizou seus estudos, prestando o exame final no ano de 1975, quando a Escola foi reaberta por um breve período de tempo.

\section{A intervenção da Escola Universitária de Serviço Social pela ditadura}

No mês de outubro de 1973, a Universidade perdeu sua autonomia, como resultado da instauração da ditadura no mês de junho desse mesmo ano, e as autoridades legitimamente eleitas foram removidas dos seus cargos. A intervenção universitária designou um advogado como diretor da Escola. Este advogado, "de direita, mas muito direito" ${ }^{9}$, tinha inicialmente como missão fechar definitivamente a Escola. No entanto, logo depois decidiu reabri-la, realizando um ajuste no currículo de 1966.

Basicamente, o que a reforma do currículo fez foi retirar algumas disciplinas do novo currículo e restabelecer algumas disciplinas do Serviço Social Tradicional, como Grupo e Comunidade em substituição de Teoria e Prática Profissional.

Nesta primeira fase da intervenção da Escola, não foi demitido nenhum docente e nenhum funcionário. Foi assim que, por exemplo, tanto Enrique Iglesias quanto Alfredo Errandonea continuaram trabalhando, e o diretor-interventor consultava os professores para tomar suas decisões. Também foi neste momento que o Professor Herman Krusse realizou concurso público para reingressar ${ }^{10}$ na Escola no ano de 1974.

\section{$O$ recrudescimento da repressão e a demissão dos professores da escola}

No ano de 1976, a Universidade começou a exigir que os seus funcionários assinassem a "declaração de fé democrática". Nesta declaração, o funcionário jurava que não tinha tomado parte de nenhuma organização de esquerda. Este era um requisito para continuar trabalhando na administração pública. Esta declaração foi assinada por todos os professores da Escola. Porém, alguns professores, além de assinar, anexaram uma nota manifestando sua discordância com esse tipo de exigência. Estes professores

\footnotetext{
${ }^{9}$ Assim foi caraterizado pelo entrevistado citado na nota de rodapé 6.

${ }^{10}$ Anteriormente Kruse tinha trabalhado na EUSS através do acordo que levou os professores da "Escola do Ministério" a passar para a escola universitária.
} 


\section{ReVistg all paUtg}

\} O PROCESSO DE RENOVAÇÃO DO SERVIÇO SOCIAL NO URUGUAI - ACOSTA, L. \}

foram: Alfredo Errandonea, Enrique Iglesias, Herman Kruse e Nibia Gerpe. Por essa atitude, estes quatro professores foram objeto de uma sindicância administrativa, e em seguida demitidos. O diretor-interventor da Escola foi contrário a este processo administrativo e à demissão dos professores e, por essa razão, ele também se demitiu junto com eles. Finalizou-se assim a primeira fase da intervenção na Escola.

Logo depois da demissão do primeiro diretor-interventor da EUSS, as autoridades interventoras da Universidade designaram outro advogado para ocupar a direção da Escola. Este, diferente do anterior, era um "fascista $^{11 "}$.

A Escola foi fechada novamente, e o diretor-interventor chamou a imprensa para denunciar a infiltração "subversiva" na Escola de Serviço Social (ele mostrou alguns livros de Marx junto com objetos que poderiam ser utilizados como armas, como, por exemplo, pedaços de madeira).

A Escola foi reaberta no ano de 1977, com um novo currículo e com um novo corpo de professores, uma vez que, todos os professores que tinham entrado por concurso no período anterior foram demitidos em função das disposições estabelecidas no Ato Institucional $\mathrm{n}^{\circ} 7$ do ano de $1977^{12}$.

\section{A resistência do movimento estudantil à ditadura}

Com este novo currículo, a Escola regredia para uma concepção baseada nos métodos tradicionais, acrescida de mais elementos próprios da ditadura, em particular a "doutrina da segurança nacional", que passou a formar parte do currículo.

No entanto, com o clima de repressão em que se desenvolviam as atividades na Universidade e em particular na Escola Universitária de Serviço Social, o movimento estudantil começou a se rearticular até conseguir se manifestar publicamente, através do Centro de Estudantes Universitários de Serviço Social ligado à Federação de Estudantes Universitários do Uruguai (CEUSS/FEUU), já no ano de 1979. As atividades se desenvolviam em condições muito especiais por causa da repressão que se exercia sobre as organizações estudantis e sindicais.

Somente a partir do ano de 1983, quando o movimento sindical organizou o primeiro ato público de massas em comemoração à data do primeiro de maio, que o movimento estudantil começou a aparecer publicamente.

Muitos dos integrantes desta primeira geração de estudantes, uma vez formados em 1981, assumiram a tarefa de reconstruir a antiga organização dos assistentes sociais - o Sindicato de Assistentes Sociais do

\footnotetext{
${ }^{11}$ Caraterização realizada pelo entrevistado citado na nota de rodapé 6 .

${ }^{12}$ Por Ato Institucional todos os funcionários públicos perderam a estabilidade no emprego ficando todos os cargos à disposição das autoridades.
} 
Uruguai (SASU) - que tinha sido ilegalizada pela ditadura em $1973^{13}$. Nesta tarefa, convergiam também os profissionais formados em anos anteriores como, por exemplo, Enrique Iglesias e um conjunto de assistentes sociais vinculados à organização não governamental Equipes Consultores Associados. (GRUPO DE ASISTENTES SOCIALES, 1981).

Desta confluência surgiu o primeiro núcleo de profissionais que reorganizou a categoria profissional em uma associação de assistentes sociais $^{14}$, a partir do ano de 1981, e obteve o reconhecimento legal no ano seguinte. No ano de 1983, foi uma das poucas organizações de profissionais que participou da comemoração do Dia Internacional dos Trabalhadores, o primeiro ato legal e de massas em que a classe operária organizada emergiu publicamente no cenário político-social ${ }^{15}$.

Particular importância teve esta organização na restauração das autoridades legítimas da Escola Universitária de Serviço Social, que teve início a partir do ano de 1984 (último ano da ditadura).

Também foi muito relevante a participação no conjunto de lutas que pautaram o processo de restauração democrática, em particular a mobilização pela anistia aos presos políticos, que demandava a liberdade de todos, com particular ênfase aos assistentes sociais que ainda estavam nos cárceres da ditadura ${ }^{16}$.

\section{O fim da ditadura e a restauração das autoridades legítimas}

Com o fim da ditadura no ano de 1985, as autoridades universitárias que estavam na direção da instituição no início do processo ditatorial voltaram a ocupar seus cargos. Assim, na Escola Universitária de Serviço Social, retornou a ocupar o cargo de diretor o Professor Enrique Iglesias, exercendo esta função até o ano de $1989^{17}$.

Começou neste momento a discussão da reestrutura da Universidade, que levou, em 1992, à criação da Faculdade de Ciências Sociais. No seu interior foi criado primeiro um Programa de Desenvolvimento do Trabalho Social e depois, a partir dele, um Departamento de Trabalho Social que substituiu a Escola.

\footnotetext{
${ }^{13}$ Infelizmente temos pouca informação sobre esta organização. Possivelmente foi criada no ano de 1970, participava como organização fraterna na CNT (Convenção Nacional dos Trabalhadores, central sindical classista e unitária fundada em 1964) e foi ilegalizada junto com o golpe de estado de 1973. Herman Kruse, Raquel Cortinas e Renée Dupont faziam parte da diretoria.

${ }^{14}$ Associação de Assistentes Sociais do Uruguai (ADASU), hoje Associação de Assistentes e Trabalhadores Sociais do Uruguai (ADATSU).

${ }^{15} \mathrm{O}$ ato foi organizado pelo Plenário Intersindical de Trabalhadores (PIT), organização classista e unitária que reivindicava o legado da Convenção Nacional dos Trabalhadores (CNT) que tinha sido ilegalizada pela ditadura após a greve geral de 1973 em resposta ao golpe de estado.

${ }^{16} \mathrm{Na}$ ADASU foi criada uma Comissão de Direitos Humanos que centralizou o trabalho de denúncia e assistência aos presos políticos tanto quanto o retorno dos exilados.

${ }_{17}$ Assim aconteceu com todas as autoridades universitárias; todas elas voltaram a ocupar os mesmos cargos dos quais tinham sido afastados.
} 


\section{AeVistg all paUtg}

\} O PROCESSO DE RENOVAÇÃO DO SERVIÇO SOCIAL NO URUGUAI - ACOSTA, L. \}

A direção da Escola neste último ano da sua existência foi exercida pela Professora Teresa Porzecanski (anos de 1990 até 1993). Uma vez criado o Departamento de Trabalho Social, foi a Professora Cristina Rovira quem ocupou o cargo nos últimos anos do currículo de 1967, que se finalizou em 1995.

\section{Quadro 1}

Currículos da Escola Universitária de Serviço Social: 1958-1992

\begin{tabular}{|c|c|c|}
\hline Ano da reforma curricular & Ajuste & Comentário \\
\hline 1959 & & $\begin{array}{l}\text { A escola inicia suas atividades no ano de } 1957 \text {, mas o } \\
\text { primeiro currículo, de orientação para-jurídica, só é } \\
\text { aprovado em } 1959 \text {. }\end{array}$ \\
\hline 1967 & 1971 & $\begin{array}{l}\text { Currículo desenvolvimentista em que se distinguem os } \\
\text { níveis macro e microssocial. No ano de } 1971 \text { realiza-se } \\
\text { um ajuste no ciclo profissional na busca de uma maior } \\
\text { integração teórico-prática profissional. Momento de auge } \\
\text { da discussão metodológica ("metodologismo" profissio- } \\
\text { nal). }\end{array}$ \\
\hline 1967 & 1974 & $\begin{array}{l}\text { No ano de } 1973 \text { as atividades da Universidade serão } \\
\text { clausuradas pela ditadura. No ano seguinte, ajusta-se o } \\
\text { currículo, retornando aos métodos tradicionais preser- } \\
\text { vando a orientação desenvolvimentista do currículo de } \\
1967 \text {. A bibliografia mais crítica é expurgada dos pro- } \\
\text { gramas das disciplinas. Este ajuste tem uma duração de } \\
\text { apenas um ano (foi o currículo da geração que ingressou } \\
\text { em 1975). No ano de } 1975 \text { a escola será novamente fe- } \\
\text { chada e somente será reaberta no ano de } 1977 \text {, com um } \\
\text { novo currículo e uma nova direção. }\end{array}$ \\
\hline 1977 & & $\begin{array}{l}\text { Currículo que não apenas restaura os métodos tradi- } \\
\text { cionais como também muda a orientação geral, que } \\
\text { deixa de ser desenvolvimentista e passa a ter uma orien- } \\
\text { tação paramédica acrescida com a "doutrina da segu- } \\
\text { rança nacional". }\end{array}$ \\
\hline 1967 (cont.) & 1987 & $\begin{array}{l}\text { No ano de } 1985 \text {, restaura-se o currículo de } 1967 \text { e, no } \\
\text { ano de } 1987 \text {, realizam-se ajustes no ciclo profissional } \\
\text { com a criação das oficinas de teoria e prática profissional } \\
\text { em substituição aos métodos tradicionais }\end{array}$ \\
\hline
\end{tabular}

Como pode ser observado no quadro No. 1, houve basicamente três currículos ao longo dos trinta e cinco anos de vida da Escola Universitária de Serviço Social ${ }^{18}$. O primeiro, que inaugurou os cursos em 1957, foi aprovado no ano de 1959 (dois anos depois de iniciados os cursos). Foi rapidamente questionado, dando lugar à discussão sobre o novo currículo, aprovado no ano de 1966, sendo o currículo que dominou a vida desta Escola até sua (auto)dissolução em 1993, com a interrupção que significou o período ditatorial entre 1973 e 1984. Foi quando vigorou, a partir de 1977, outro currículo por um período de oito anos (na primeira fase de in-

\footnotetext{
${ }^{18}$ Uma análise comparativa entre os currículos da Escola Universitária de Serviço Social pode ser encontrada em Carlos Montaño (1994).
} 
tervenção da ditadura na Escola, continuou a vigorar o currículo de 1966 com alguns ajustes no ciclo profissional). Na restauração democrática, o currículo de 1966 foi modificado a partir de 1987, fundamentalmente no ciclo profissional quando se implementou as "oficinas de teoria e prática profissional", como veremos mais à frente.

O processo de renovação do Serviço Social que estamos analisando se identifica praticamente com a vigência do currículo de 1967, em todo período que abarca desde 1967 até 1992, quando ingressou a última geração de estudantes que cursou seus estudos no marco desse currículo, sendo também a última geração a ingressar na Escola Universitária de Serviço Social.

Este período de vinte e cinco anos inclui a "interrupção" provocada pela ditadura entre os anos de 1977 e 1984, no currículo de 1967, já que ainda nesse momento a referência em relação ao perfil do assistente social (até para os próprios estudantes) era aquele outro currículo.

\section{A criação da Faculdade de Ciências Sociais e o fim da Escola Universitária de Serviço Social}

O processo de criação da Faculdade de Ciências Sociais deu lugar a um debate sobre o caráter do Serviço Social, no período da restauração democrática e da reconstrução e reforma da Universidade ${ }^{19}$. O problema que se colocou foi a reestruturação da Universidade para se adaptar à "terceira revolução técnico-científica." A proposta era enfrentar a orientação "profissionalista" que tinha vigorado até esse momento na Universidade, e passar para uma nova estrutura baseada na íntima relação entre o conhecimento "puro" ou "básico" e o conhecimento "aplicado" ou "tecnológico". O fundamento desta discussão era a diminuição do tempo entre a descoberta de um novo princípio, o fato científico e sua aplicação tecnológica quase imediata na produção.

Nesse contexto, a proposta que se discutiu na Universidade foi a de fortalecer o núcleo das disciplinas básicas para que essas subsidiassem as disciplinas aplicadas, diferenciando-as e, ao mesmo tempo, integrandoas. Os debates não estavam localizados no diagnóstico, nem tampouco na solução, e nem na abrangência e velocidade das mudanças que a Universidade deveria implementar.

No final, predominou uma estratégia "gradualista", que teve como resultado a criação de duas novas faculdades que deveriam ter como propósito o cultivo do conhecimento básico. Uma dessas faculdades seria a Facul-

19 Um processo semelhante aconteceu com a escola "católica". Deve ser sublinhado que no último ano da ditadura -1984-, foi autorizada pela primeira vez na história do Uruguai o funcionamento de uma universidade privada, o que deu lugar ao surgimento da Universidade Católica "Dámaso Antonio Larrañaga", que incorporou a Escola de Serviço Social do Uruguai. Neste caso também a Escola foi incorporada na forma de departamento da Faculdade de Ciências Sociais Aplicadas. 


\section{AeVistg all paUtg}

\} O PROCESSO DE RENOVAÇÃO DO SERVIÇO SOCIAL NO URUGUAI - ACOSTA, L. \}

dade de Ciências Exatas e Naturais; a outra, a Faculdade de Ciências Sociais. Ambas se constituiriam em "polos" do desenvolvimento do conhecimento básico, que seria logo depois aplicado (ou incorporado) tecnologicamente pelas disciplinas profissionalizantes (assim, por exemplo, a relação entre a biologia e a medicina) e, por esse caminho, se chegaria ao setor produtivo.

O problema que se colocou foi o que deveria ser feito com o Serviço Social, ou, melhor dizendo, com a Escola Universitária de Serviço Social, que dependia diretamente do Conselho Diretor Central da Universidade. A Escola tinha, e obviamente ainda tem, um caráter nitidamente profissionalizante, já que sua razão de ser fundamental é atender às demandas do mercado de trabalho por profissionais aptos para enfrentar as refrações da "questão social", no âmbito das políticas sociais.

$\mathrm{Na}$ Escola se discutiu intensamente o seu futuro destino (que também era o destino do próprio Serviço Social no Uruguai). O dilema estava no fato de que a Escola queria sair da dependência direta do Conselho Diretor Central da Universidade (também o Conselho não queria ter sua responsabilidade em nenhuma escola) e passar a integrar a nova Faculdade de Ciências Sociais, em igualdade de condições com as outras disciplinas (portanto não como Escola anexa à faculdade).

A dificuldade desta estratégia para o Serviço Social estava em sua natureza interventiva ("profissionalista"); a Escola não se encaixava na proposta de uma faculdade voltada para a produção do conhecimento básico no campo das ciências sociais. A "solução", que finalmente se encontrou, foi a criação da Faculdade de Ciências Sociais com a Escola de Serviço Social em seu seio.

No entanto, a Escola foi sendo gradualmente fechada, e no seu lugar foi criado o Departamento de Trabalho Social. Este departamento (e a mudança de nome) significava também uma vontade por parte do Serviço Social de alcançar um novo patamar no processo de amadurecimento acadêmico, passando de técnico para um intelectual (produtor de conhecimentos básicos ou fundamentais no âmbito das ciências sociais), na tentativa de manter uma relação "entre iguais" com as outras ciências sociais.

\section{Perspectivas ou tendências no Serviço Social do Uruguai a partir do processo de renovação profissional}

O processo de renovação do Serviço Social no Uruguai deu lugar ao surgimento de diversas correntes de pensamento, sendo isto o que constituiu a novidade desse período (a heterogeneidade do debate profissional - o pluralismo - e a incipiente conformação de uma cultura profissional relativamente autônoma em face às outras profissões).

Este processo está umbilicalmente unido aos avanços alcançados na conformação da classe operária como sujeito político que se materializou 


\section{Revista pll paעtg}

\} O PROCESSO DE RENOVAÇÃO DO SERVIÇO SOCIAL NO URUGUAI - ACOSTA, L.

na unidade do movimento sindical, na Convenção Nacional dos TrabaIhadores (CNT), em 1964, e a unidade da classe operária com as camadas médias urbanas, materializadas politicamente na conformação da Frente Ampla (FA), em 1971, durante os anos sessenta e no início dos anos setenta do século passado. Este processo refrata-se na esfera cultural e, por essa via, na cultura profissional, dando lugar ao processo de renovação profissional.

Na década de sessenta, o Serviço Social iniciou um processo de questionamento que fazia parte de um movimento mais amplo de crítica à ordem social burguesa e à inserção subordinada da economia uruguaia nas relações internacionais (em particular no que diz respeito às relações com os EUA).

Neste quadro, começou a se constituir um conjunto de perspectivas de análise da profissão, com foco principalmente nos seus processos interventivos e menos no "ser" (a natureza sócio-histórica) do Serviço Social. É claro, no entanto, que em toda discussão sobre os processos interventivos trabalha-se com uma pré-compreensão da "natureza" do Serviço Social.

Nem toda a produção teórica pode ser enquadrada em linhas muito marcadas. Assim, por exemplo, Ricardo Hill, Scarón de Quinteros, e Teresa Porzecansky não podem ser identificados em uma corrente determinada, tendo feito importantes contribuições para a renovação do Serviço Social naquela época. Renée Dupont também tem um lugar muito particular no desenvolvimento do Serviço Social daqueles dias, já que, mesmo se identificando com o grupo que gravitava em torno da equipe de pesquisa de Enrique Di Carlo, teve uma intervenção bastante diferenciada, em certa medida mais sintonizada com o debate reconceitualizador na América Latina, o que não pode ser estendido para todos os integrantes dessa equipe.

Sustentamos que é possível identificar algumas tendências sóciohistóricas surgidas no Serviço Social do Uruguai que, em ordem cronológica, são:

- Desenvolvimentista

- Comunicação racional

- Sociológica ou modernizadora

- Educação popular

A perspectiva desenvolvimentista foi inspirada no diagnóstico prebischiano da CEPAL, da Aliança para o Progresso (1961) da Organização dos Estados Americanos, e na análise da Comissão de Investimentos e Desenvolvimento Econômico (CIDE) (esta última criada pelo governo uruguaio em 1960). Foi assumida por Herman Kruse já no período pré-67.

O currículo da Escola Universitária de Serviço Social (EUSS) de 1966 foi influenciado por esta concepção, ainda que na implementação deste currículo a perspectiva desenvolvimentista tenha sido superada por uma concepção sociológica ou modernizadora do Serviço Social, que só 


\section{ReVistg all paUtg}

\} O PROCESSO DE RENOVAÇÃO DO SERVIÇO SOCIAL NO URUGUAI - ACOSTA, L. \}

amadureceria mais à frente, durante a ditadura (daí o relativo isolamento em que ficou progressivamente a figura de Herman Kruse na EUSS).

Em verdade, na própria concepção do currículo de 1966 já estava presente a concepção sociológica na divisão entre o ciclo básico (os dois primeiros anos) e o ciclo profissional (os três últimos anos), sendo que o papel daquele primeiro ciclo é fornecer uma sólida formação no campo das ciências sociais junto com os fundamentos do Serviço Social.

Neste mesmo período, surgiu também a perspectiva da comunicação racional articulada em torno da figura da equipe de pesquisa de Enrique Di Carlo, que buscava no interacionismo simbólico dos fundadores do Serviço Social (notadamente Mary Richmond) os fundamentos do Serviço Social (DI CARLO, 1997).

Nesta perspectiva, opera-se uma divisão entre o nível macrossocial e o nível microssocial, sendo que a prática social, no nível macrossocial, é a prática das classes e dos partidos políticos (não dos assistentes sociais), enquanto que a prática profissional é uma prática microssocial (nas relações sociais interpessoais) onde operam os assistentes sociais. As transformações sociais acontecem no nível macrossocial e, portanto, são levadas adiante pelos partidos políticos (não pelos grupos profissionais). Assim, se os assistentes sociais procuram transformar a sociedade devem se deslocar da prática profissional para o espaço dos partidos políticos, sindicatos e movimentos sociais.

Para estes autores, o trabalho do assistente social é explicado a partir do interacionismo simbólico em que se fundamentaram os fundadores do Serviço Social clássico. De forma muito sintética, pode-se dizer que a prática do assistente social consiste num trabalho de "consciência à consciência" entre o profissional e o usuário, no qual se processa a transformação do "concreto sentido em concreto pensado" através do diálogo profissional.

Estas duas perspectivas (desenvolvimentista e da comunicação racional) estão atreladas à existência de um mercado de trabalho profissional estruturado, basicamente, a partir da intervenção estatal direta nas refrações da "questão social", em um contexto democrático (quer dizer também que estão atreladas ao "Uruguai clássico": liberal, democrático e reformista). Enquanto que, na concepção desenvolvimentista, o assistente social ocupa (ou pretende ocupar) os novos espaços sócio-ocupacionais, criados pela crescente participação do Estado nas tarefas de planejamento para o desenvolvimento; na concepção da comunicação racional, o assistente social ainda está vinculado aos espaços sócio-ocupacionais tradicionais (saúde, infância e adolescência e família) como um profissional do Estado de Bemestar social do reformismo "batllista", que desenvolve sua prática profissional no espaço microssocial como "operador terminal das políticas sociais".

Temos aqui, nessas duas perspectivas, o encontro entre o "velho" reformismo, que tem suas raízes nos processos de modernização do início do século XX (incluído aqui os momentos "jacobinos"), com o "novo" de- 


\section{Revista pll paעtg}

\} O PROCESSO DE RENOVAÇÃO DO SERVIÇO SOCIAL NO URUGUAI - ACOSTA, L. \}

senvolvimentismo dos anos cinquenta, como expressão da nova situação mundial provocada pela afirmação da hegemonia norte-americana no pósguerra (a hegemonia dos monopólios).

A instauração da ditadura (1973-1984) e a consequente perda da autonomia da Universidade e a perseguição aos professores mais engajados com os partidos e movimentos democráticos e revolucionários, trazem como resultado a interrupção do desenvolvimento destas tendências. A situação agrava-se pelo desinteresse por parte da ditadura pelo desenvolvimento da Universidade, já que o projeto ditatorial era um projeto desindustrializador, em que a instituição universitária não tinha um papel relevante. No entanto, nos espaços extra universitários continuam a se desenvolver algumas tendências que já estavam começando a se gestar naquele outro período.

Foi assim que se desenvolveu e alcançou o amadurecimento da perspectiva sociológica ou modernizadora, encarnada principalmente (mas não exclusivamente) pelo grupo de assistentes sociais vinculados à organização "Equipos Consultores Asociados"20 (que continua e aprimora os fundamentos do currículo de 1966). Esta tendência se diferencia da perspectiva desenvolvimentista que não tem como principal alvo realizar mudanças macrossociais (seria como retirar os objetivos desenvolvimentistas, ficando apenas com o instrumento do planejamento).

O fundamento desta concepção está no "desenho lógico de projetos", que é uma metodologia de formulação de projetos sociais que se integra ao processo de intervenção profissional e à gestão de recursos (teoria de administração) com hipóteses teóricas (teorias sociais de alcance médio). Sendo assim, integram a teoria com a prática.

O processo de intervenção profissional orientado por esta concepção possibilita distinguir os problemas de gestão de recursos dos problemas teóricos, permitindo que se verifiquem, através da prática profissional, hipóteses teóricas.

A outra perspectiva que amadureceu durante o período ditatorial foi a perspectiva da educação popular, que tinha no Centro de Investigação e Desenvolvimento Cultural (CIDC) sua principal base institucional. Esta última perspectiva trabalha a partir das formulações do educador brasileiro Paulo Freire, interpretado por vezes à luz das ideias do dirigente comunista italiano Antônio Gramsci. Nesta perspectiva, o trabalho do assistente social pode ser caracterizado como um trabalho de educação que transforma o "senso comum em bom-senso" das camadas populares.

Como já foi sublinhado, possivelmente ambas as perspectivas começaram a se desenvolver durante o período anterior, mas só alcançaram visibilidade durante a ditadura nos espaços extra universitários constituídos pelas organizações não governamentais daquela época, que eram também de oposição ao regime ditatorial.

20 Não era propriamente uma organização não governamental, já que era uma pequena empresa de serviços na área de consultoria, assessoria e marketing. 


\section{ReVistg all paUtg}

\} O PROCESSO DE RENOVAÇÃO DO SERVIÇO SOCIAL NO URUGUAI - ACOSTA, L. \}

Estas últimas duas tendências estão relacionadas ao mercado de trabalho profissional de uma forma diferente daquelas outras duas do período pré-ditatorial. Agora temos uma intervenção profissional a partir da mudança na forma de intervenção estatal na sociedade, que se caracteriza pela intervenção indireta, através da sociedade civil. Nos dois casos, os assistentes sociais trabalham com os usuários a partir de organizações não governamentais.

Esta "ampliação", e também o deslocamento em relação às suas áreas tradicionais de trabalho profissional, já tinha começado a acontecer no período pré-ditatorial com a criação dos Institutos Técnicos que trabalhavam na área da moradia popular a partir das possibilidades criadas pela Lei no 13.728 de 1968 (Lei de Moradia), que foi a última grande lei social aprovada antes do início da ditadura (URUGUAI, 1968).

Apesar desta identidade, existe uma oposição fundamental entre estas duas concepções. Enquanto que, na "educação popular", procura-se desenvolver a "consciência" a partir da reflexão sobre a prática social de (auto)organização dos setores populares, na concepção "modernizadora" são hierarquizados os processos organizacionais, já que sustentam estes profissionais. Os avanços sociais (em "consciência") dependem da viabilidade econômica (ou produtiva) dos programas sociais.

Enquanto os projetos de "educação popular" dependem da "ajuda internacional" para se efetivarem (por isto não estão preocupados principalmente com o sucesso produtivo e/ou econômico), os projetos orientados pelo "desenho lógico de projetos" dependem da capacidade do próprio "sistema-cliente" de gerar seu sustento econômico (o modelo de "sistemacliente" em que estão pensando estes assistentes sociais são as cooperativas de produção).

Para os assistentes sociais vinculados a esta última perspectiva era muito claro que, no Uruguai do final dos anos setenta, esta forma de trabalho profissional era a mais dinâmica e criativa, enquanto que na "educação popular" se reproduzia, com uma linguagem teoricamente mais avançada, o Serviço Social "tradicional":

En el caso del Uruguay, las experiencias profesionales más dinámicas y creativas advienen - en nuestra opinión - del campo de los proyectos que se plantean como elemento central su viabilidad económica sustantiva, mientras que, en general, aquellos que dependen puramente del financiameiento externo tienden muchas veces a reproducir - en un esquema teóricamente avanzado - pautas muy tradicionais de se servicio social 'benefactor'. (GERPE DE BELLINI, 1980, p. 206)

Durante a re-institucionalização da democracia (a partir de 1985) e da vida universitária, estas tendências se explicitaram claramente quando, em 1987, e como forma de "aggiornamento" do ciclo profissional do velho 


\section{Revista pll paעtg}

\} O PROCESSO DE RENOVAÇÃO DO SERVIÇO SOCIAL NO URUGUAI - ACOSTA, L.

currículo de 1966 (que ainda falava dos métodos de "caso", "grupo", e "comunidade"), criaram-se as "oficinas" de teoria e prática profissional ${ }^{21}$.

As oficinas são uma modalidade pedagógica, nas quais se acredita que é possível organizar o ensino da prática de uma forma tal, que possibilita a superação da dicotomia entre teoria e prática. A organização do ensino da prática na forma de oficina é claramente uma reivindicação do movimento de reconceituação, que buscava renovar o ensino tradicional - a educação "bancária", utilizando a terminologia de Paulo Freire (1987) baseado na aula magistral.

A oficina " $A$ " trabalhava com a perspectiva da comunicação racional; a oficina "B", com a perspectiva sociológica ou modernizadora; a oficina " $C$ ", com a perspectiva da educação popular. A única tendência que não está presente é a "desenvolvimentista", ainda que possa estar subsumida na perspectiva modernizadora (a oficina " $\mathrm{C}$ " definia sua área de intervenção como "desenvolvimento local"). Havia também outra oficina (a " $\mathrm{D}^{\prime \prime}$ ) que não tinha afinidade com nenhuma destas tendências e, por essa mesma razão, tinha pouca expressão no debate no interior da escola daqueles dias.

Com a dissolução da escola (e, com ela, das oficinas) e a criação do Departamento de Trabalho Social, em 1993, na Faculdade de Ciências Sociais, com um novo currículo, cria-se também a pós-graduação (1997). Nela, inicia-se a recepção das contribuições do Serviço Social do Brasil vinculadas à perspectiva da "intenção de ruptura" e ao "projeto ético-político" (por esta causa é conhecida informalmente como "brasileira" ou também "da UFRJ"), que colide em certos aspectos com a orientação básica do currículo vigente.

Este outro momento tem na figura de Carlos Montaño, através da Biblioteca Latino-americana da editora brasileira Cortez e do seu livro, "A natureza do Serviço Social" (MONTAÑO, 1998), uma de suas expressões emergentes mais conhecidas.

Mas, ao mesmo tempo, com a dissolução desta Escola termina também o processo (ou uma fase de longa duração) de renovação do Serviço Social inspirada nos acontecimentos revolucionários dos anos sessenta (em particular daquilo que designamos como "cultura radical"). A fundação da Faculdade de Ciências Sociais e o Departamento de Trabalho Social se alimentam de outros ventos mais contemporâneos - após o furacão revolucionário dos anos sessenta.

A mudança de nome (Trabalho Social por Serviço Social) é um sintoma dessa passagem de uma época para outra. De um lado, expressa a vontade de ruptura ou a "intenção de ruptura" com as práticas assistenciais da tradição profissional (e do Estado paternalista na qual se fundamentam)

\footnotetext{
${ }^{21}$ Esta foi a mudança mais importante, contudo não foi a única. Foi criada a disciplina Política Social, e a disciplina Administração e Organização de Serviços Sociais foi dividida em duas: Planejamento e Administração (MONTAÑO, 1994).
} 


\section{heVista pll paעtg}

\} O PROCESSO DE RENOVAÇÃO DO SERVIÇO SOCIAL NO URUGUAI - ACOSTA, L. \}

e, ao mesmo tempo, a busca de uma nova identidade profissional no quadro das transformações societárias contemporâneas e no papel das ciências sociais e humanas na sociedade. 


\section{Revista pll paעtg}

\} O PROCESSO DE RENOVAÇÃO DO SERVIÇO SOCIAL NO URUGUAI - ACOSTA, L.

\section{Referências}

ACOSTA, L. Modernidad y Servicio Social: un estudio sobre la génesis del servicio social en el Uruguay. 240 f. Dissertação (Mestrado em Serviço Social) - Programa de Pós-Graduação (ESS/CFCH, UFRJ), Rio de Janeiro. 1998.

CEUSS, C. Fundamentación del proyecto de plan de estudios. Revista Universitaria de Servicio Social, Montevideo, n. 1, pp. 21-27. 1966.

CORTINAS, R. El servicio social en los países socialistas. Revista Universitária de Serviço Social, Montevideo, n. 2, pp. 59-70. 1966.

CUEVA, A. El desarrollo del capitalismo en América Latina. México: Siglo XXI. 1987.

DI CARLO, E. La escuela universitaria de servicio social. Revista Universitaria de Servicio Social, Montevideo, n. 1, pp. 5-19. 1966.

- Trabajo Social profesional: el método de la comunicación racional. Buenos Aires: Humanitas - Facultad de Ciencias de la Salud y Servicio Social / Universidad Nacional de Mar del Plata. 1997.

DUPONT, R. Estado intervencionista - Estado fascista: el caso Uruguay en política social. Comunicación presentada. Buenos Aires, mayo 1983.

FALEIROS, V. Confrontaciones teóricas de la Reconceptualización. Acción Crítica, CELATS, Lima, v. 21. 1987.

FREIRE, P. Pedagogia do oprimido, $17^{\underline{a}}$ ed. Rio de Janeiro: Paz e Terra. 1987.

GERPE DE BELLINI, N. et al. Elementos para un perfil profesional del trabajo social. Uruguai/Lima: CELATS. 1980.

GRUPO DE ASSISTENTES SOCIAIS. Estudio de viabilidad de creación de una asociación profesional en Uruguay. Acción Crítica, n. 10, pp. 29-34. 1981.

IGLESIAS, E. El servicio social en los países subdesarrollados. Revista Universitaria de Servicio Social, Universidad de la República, Montevideo, pp. 71-78. 1966.

KRUSE, H. El servicio social en los países capitalistas. Revista Universitaria de Servicio Social, n. 2, pp. 55-58. 1966.

MONTAÑO, C. Análisis de las matrices del Trabajo Social en el Uruguay a través de sus Planes de Estudio. Cuadernos de Trabajo Social, Montevideo, n. 3, pp. 45-73. 1994.

. La naturaleza del servicio social. São Paulo: Cortez. 1998. 


\section{ReVistg all paUtg}

\} O PROCESSO DE RENOVAÇÃO DO SERVIÇO SOCIAL NO URUGUAI - ACOSTA, L. \}

NETTO, J. P. Ditadura e Serviço Social: uma análise do Serviço Social no Brasil pós 64. São Paulo: Cortez. 2001.

. La crisis del proceso de Reconceptualización del Servicio Social. Selecciones del Servicio Social. Revista Latinoamericana, v. VIII, n. 26, pp. 60-75. 1975.

ORTEGA, E. El Servicio Social y los procesos de medicalización de la sociedad uruguaya en el período neobatl lista. $352 \mathrm{f}$. Tese (Mestrado em Serviço Social) - Departamento de Trabajo Social, Facultad de Ciencias Sociales/ UDELAR. 2003.

URUGUAI. Lei 12.549, de 16 de outubro de 1958. . Lei 13.728, de 17 de dezembro de 1968.

Recebido em 15 de agosto de 2014.

Aprovado para publicação em 17 de agosto de 2014. 


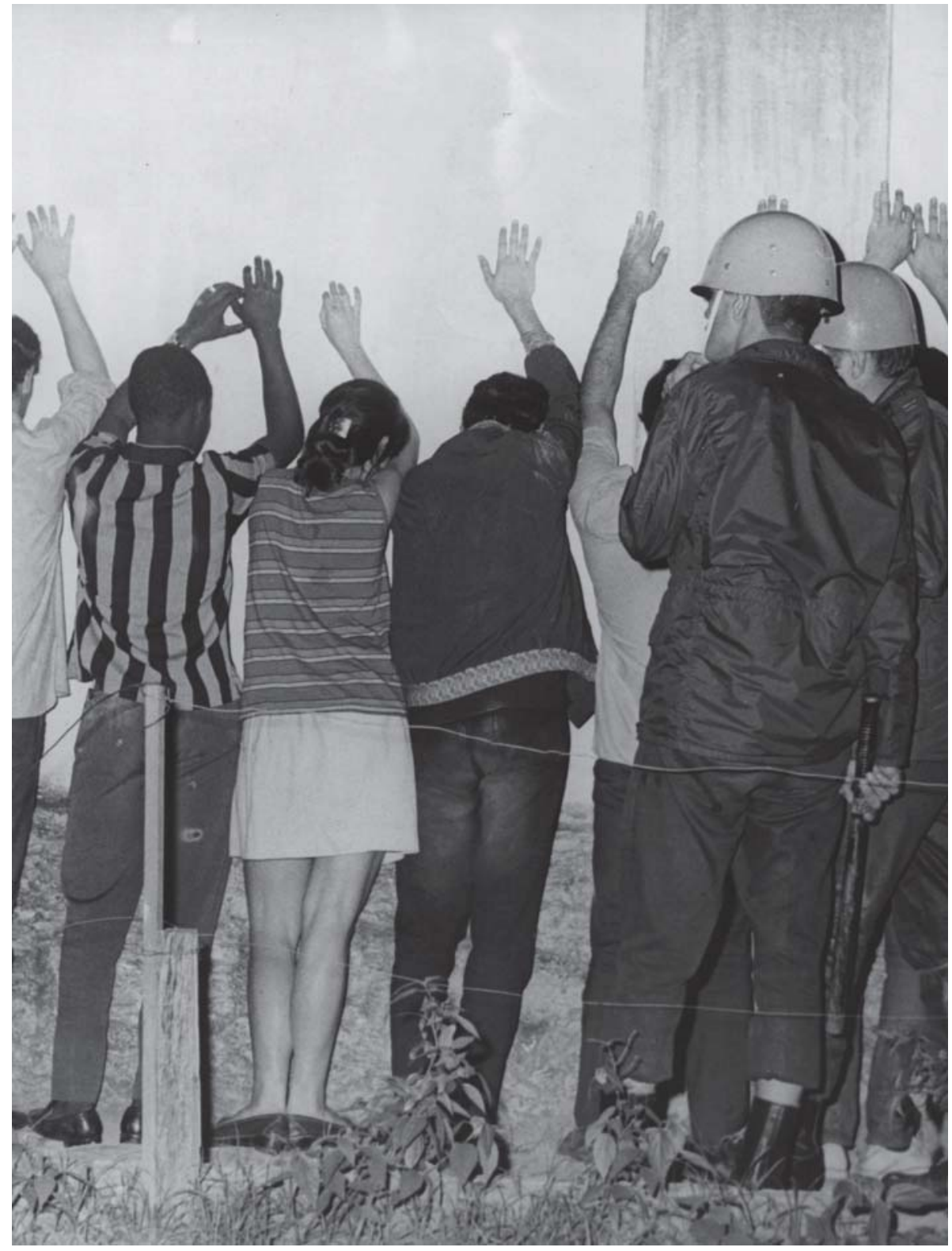

Estudantes presos. Rio de Janeiro. 1968. Correio da Manhã. Arquivo Nacional. 